\title{
Aprendendo com uma nova experiência de licenciatura
}

\section{Learning with a new experience in teacher training}

\author{
Menga Lüdke*
}

\begin{abstract}
Resumo
O texıo apresenta a proposia de um novo curso de licencialura em Matemática, Física e Química para portadores de diploma de engenheiro e comenta aspectos positivos e negativos de sua implementação.
\end{abstract}

Palavras-chave: Formação de professores. Licenciatura. Ensino médio.

\begin{abstract}
The paper presents the proposal of a new course for teacher training, open 10 engineers who wish to 1each Mathmalics, Phisics, or Chemistry in seeondary schools. Positive and negative aspects of the new course are discussed.
\end{abstract}

Key words: Teacher training. Secondary education. Science education.

\section{Introdução}

Neste texto proponho discutir algumas lições aprendidas com a vivência de uma nova proposta para o curso de licenciatura, a Licenciatura Especial para Portadores de Diploma de Engenharia da PUC-Rio. Ela nasceu a partir de uma controvertida iniciativa do Ministério da Educação, em 1997, voltada para enfrentar o grande problema da falta de professores da educação básica, de modo especial em determinadas matérias, em todo o País. Como fazia parte do Conselho Nacional de Educação nessa época, pude acompanhar de perto a evolução da proposta governamental dentro daquele órgão e o embate por ela sofrido frente à comunidade educacional, do que resultou a Resolução n. 2 de 1997, que abriu

*Professora Tilular da Pontifícia Universidade Católica do Rio de Janeiro. Endereço: Rua Marquês de São Vicente, 225 - Gávea - Rio de Janeiro - CEP: 22453-900. E-mail: menga@edu.puc-rio.br 
a possibilidade de criação da nova modalidade de licenciatura. Já tive oportunidades de comentar minhas impressões a respeito de todo esse processo e da Resolução dele resultante (Lüdke,1998 e 2000). Nesta oportunidade gostaria de trazer para discussão alguns aspectos da experiência desenvolvida pela PUCRio, que têm revelado pontos muito interessantes, pela sua ligação com os crônicos problemas enfrentados pelos cursos de formação de professores em nosso país. Para me auxiliar na indicação e na reflexão sobre esses pontos, entrevistei o professor de Prática de Ensino de Física, do novo curso, e dois recém licenciados, um em física, outro em matemática, a quem muito agradeço. Antes de passar à consideração dos pontos específicos, vou apresentar de modo sumário a evolução da proposta do MEC até a Resolução do CNE e introduzir a proposta desenvolvida pela PUC-Rio. Utilizo, para isso, parte do meu texto incluído no livro de Souza e Ferreira (Orgs.). Bacharel ou Professor? O processo de reestruturação dos cursos de formação de professores no Rio de Janeiro. Rio de Janeiro: Quartet, 2000. p. 135-144.

\section{Da proposta do MEC à Resolução 2/97 do CNE}

A proposta apresentada pelo MEC ao Conselho Nacional de Educação (CNE), no início do ano de 1997, estava marcada por uma série de características que há muito vêm sendo criticadas pelos que se dedicam ao estudo da formação de professores, de modo especial a composição de um currículo dentro de uma perspectiva disciplinar, com matérias oferecidas de maneira estanque e fragmentária, não superando a tradicional separação entre a formação teórica e prática.

O Conselho Nacional de Educação recebeu a proposta do MEC com bastante perplexidade, reconhecendo que ela não correspondia às soluções almejadas para os problemas relativos à falta de professores no país. Entretanto, os conselheiros admitiram a necessidade de reconhecer como inevitável o enfrentamento urgente da questão, assim como a ação precipitada do MEC a seu respeito. A comissão constituída no CNE para o estudo da questão, em janeiro de 1997, percebeu que, frente à urgência da solução e à inevitabilidade da medida governamental, a atitude mais adequada seria procurar melhorar, dentro do possível, a proposta do MEC. Assim, os membros dessa comissão procuraram estudar dentro do prazo exíguo estipulado pelo Ministério as possíveis sugestões para melhoria da proposta original. Nesse esforço foram feitas inúmeras consultas às associações especificamente dedicadas ao estudo da formação de professores, como a Anfope e a ANPEd, tendo sido realizada 
uma audiência pública com representantes dessas e de outras associações, para discussão da proposta reformulada a ser encaminhada ao Ministério.

$\mathrm{O}$ trabalho da comissão do $\mathrm{CNE}$ e as contribuições dos representantes das associações mencionadas acabaram por produzir uma proposta que, embora bastante limitada, consegue apresentar algumas sugestões aproximadas de idéias defendidas há muito tempo por estudiosos da formação de professores. Entre elas se destaca a concepção do currículo centrado em núcleos, que focalizariam os temas centrais que devem integrar a formação do futuro professor, em lugar das tradicionais disciplinas. Ao trabalhar ao redor desses temas seria possível reunir a contribuição das várias disciplinas, que vêm sendo oferecidas de forma isolada e estanque nos cursos da licenciatura regular. Dessa forma se poderia assegurar o aproveitamento do saber acumulado por aquelas disciplinas, na discussão dos problemas básicos enfrentados pela nossa educação, numa perspectiva bem mais orgânica e aproximada das questões que serão enfrentadas pelos futuros professores em seu trabalho.

Outra idéia central da proposta reformulada é a integração entre a formação teórica e a prática. Para isso se deveria levar em conta a experiência de trabalho e a formação anterior do futuro professor, examinando-se cuidadosamente seu histórico escolar, para assegurar que cobre os conhecimentos básicos da área específica. Para sua formação como professor será preciso, entretanto, que lhe seja garantida uma preparação específica para o ensino da matéria que irá lecionar para alunos da educação básica. Isto implicaria uma efetiva prática de trabalho interdisciplinar, na qual se integraria o trabalho de professores dos diferentes departamentos da universidade, responsáveis pelos vários domínios do saber (Física, Química, Matemática, Geografia, História, Línguas, Artes, Educação Física, Biologia, Filosofia) e o trabalho de professores do departamento de Educação.

A integração entre teoria e prática na formação do futuro professor deveria ser amparada também pelo desenvolvimento da prática de ensino ao longo de todo o curso e não apenas ao seu finnal, como usualmente vem sendo feito nas licenciaturas regulares, sob a forma de estágios. Essa prática deveria ser centrada nas questões relativas ao campo de docência pretendido pelo futuro professor $\mathrm{e}$ nas estratégias de ensino mais apropriadas a esse campo. Ela deveria envolver não apenas os trabalhos de docência efetiva, em sala de aula, como também todas as atividades da escola, seja no âmbito administrativo, no planejamento curricular, conselhos de classe, reuniões com a comunidade, festas, competições, entre outras. É importante que o futuro professor se inteire dos problemas relativos a todos esses aspectos da vida da escola, além, é claro, de ter sob sua 
responsabilidade, ao menos durante algum tempo, uma turma de alunos. Somente assim ele poderá se conhecer no exercício da função docente e procurar se preparar nos aspectos em que se sente inseguro.

Não apenas a importância do caráter emergencial de um tal programa foi encarecida nas muitas discussões sobre a proposta do Ministério pelos membros do CNE. Também foi muito discutida a limitação da proposta a uma simples medida parcial, de emergência, para remediar a falta de professores em determinadas disciplinas e em algumas regiões do País. Ficou claro, nas discussões no $\mathrm{CNE}$, que não se tratava da formulação de uma política geral sobre a formação de professores para todo o País, como reclamava (e continua a reclamar) a comunidade educacional. A formulação de uma tal política deveria prever não apenas uma preparação complementar de profissionais de outras áreas, mas planejar medidas e ações que valorizem a formação e a carreira profissional do professor (inclusive no que se refere a condições de trabalho e salários), tornando-as confiáveis e atraentes, para assegurar a permanência dos que nelas se encontram hoje e a entrada de futuros profissionais.

Nessas discussões foi igualmente lembrada a importância de se dispor de dados estatísticos que indiquem com segurança onde se localizam as verdadeiras carências de professores nas mencionadas disciplinas, pois é corrente a afirmação de que há cidades e mesmo Estados que dispõem de um número mais do que suficiente de professores habilitados, que não se dirigem ao magistério, preferindo buscar carreiras mais atraentes, até em outros países. Essas e outras questões foram objeto das muitas discussões que a proposta do Ministério provocou entre os membros do Conselho e da comunidade educacional em geral, numa reação natural provocada pela frustração de ver uma proposta tão reduzida e talvez até redutora em lugar da proposição de uma política que viesse ao encontro de expectativas há muito tempo acalentadas.

\section{A Licenciatura Especial para Engenheiros da PUC-Rio}

Em 1998, o Departamento de Engenharia da PUC-Rio encaminhou ao Decanato do Centro Técnico Científico (CTC) uma proposta sugerindo a implantação de um curso de Licenciatura Especial para Portadores de Diploma de Nível Superior, com o objetivo de oferecer a engenheiros a opção de se tornarem professores de Física, Química ou Matemática.

O CTC aceitou a proposta e os Departamentos de Educação, Engenharia, Matemática, Física e Química foram convocados a planejar e implantar em conjunto esse novo curso. Houve, inicialmente, uma certa hesitação por parte 
dos professores do Departamento de Educação, que acabaram por visualizar na implantação desse novo curso uma boa oportunidade para repensar a licenciatura regular tradicionalmente oferecida pela universidade, apesar da consideração às críticas levantadas em toda a comunidade educacional em relação à resolução que criou a nova licenciatura (Resolução 2/1997 do CNE). Ainda no ano de 1998, aqueles departamentos envolveram-se num intenso processo de planejamento, que culminou na criação do curso de Licenciatura Especial para Portadores de Diploma de Engenharia da PUC-Rio.

$O$ processo de articulação entre os diferentes departamentos envolvidos procurou integrar as áreas exatas e humanas, tradicionalmente distantes, através da discussão dos aspectos centrais à formação do futuro professor, a serem assumidos conjuntamente pela contribuição de cada domínio específico e da área de educação. Nesse esforço comum, cada departamento se propôs a oferecer os componentes necessários para a preparação do novo professor. Assim, os Departamento de Física, Matemática e Química propuseram a participação dos alunos ingressados no novo programa em cursos já oferecidos na graduação e na pós-graduação. O Departamento de Educação, por sua vez, desenvolveu um considerável esforço por parte de todos os seus professores para selecionar os conteúdos essenciais para compor um currículo próprio para a formação desse novo professor. Desse esforço resultaram quatro conjuntos de temas, extraídos das diferentes disciplinas trabalhadas no departamento, cobrindo questões cuja discussão deve integrar essa formação. São eles:

Educação e Sociedade: A educação como processo de socialização e transmissão cultural. A escolarização desigual, suas explicações e implicações. A democratização da escola: possibilidades e limites. A relação escola/cultura(s): desigualdades e diferenças; universalidade e relativismo; multiculturalismo e interculturalismo. A escola como instituição social: currículo, saber docente e cultura escolar. Questões atuais: violência e questões urbanas; mídia e sociedade de massa; escola e comunidade.

História e Política da Educação Básica: Perspectiva histórica da política educacional brasileira para a Educação Básica. $O$ contexto pós-64. Ampliação do acesso à escola de $1^{\circ}$ grau e profissionalização do ensino de $2^{\circ}$ grau. A década de 80 e os desafios da transição democrática para a escola pública de $1^{\circ}$ e $2^{\circ}$ graus: experiências e propostas. As principais questões em debate nas décadas de 80-90: a relação escola-trabalho-tecnologia, a relação públicoprivado e o tema da qualidade em educação. Características das ações e propostas atuais do governo para a Escola Básica (Educação Fundamental e Média). 
$O$ processo de construção do conhecimento na escola: A constituição do sujeito e a construção da imagem do conhecimento: subjetividade, diversidade, singularidade. A intersubjetividade e as questões de comunicação. $O$ desenvolvimento humano através do ciclo vital. As diferentes formas de aprender. As expressões de cada faixa etária e as influências culturais. Recursos do sujeito e recursos do meio na construção do conhecimento. A escola enquanto organização: a aprendizagem social. A sala de aula e as questões específicas da relação professor/aluno. Perspectivas da escola do Terceiro Milênio.

$O$ trabalho docente e suas várias dimensões: $\mathrm{O}$ professor, a professora, sua formação e profissão. $O$ desenvolvimento na carreira e as condições de trabalho. Diversidade e cotidiano escolar. A sala de aula: lugar da prática didática, da construção do conhecimento, da comunicação e da cultura. Instrumentalização do trabalho docente: o papel das técnicas didáticas e dos recursos tecnológicos. A avaliação escolar: sua contestação e relevância. A disciplina escolar: releitura de um tema polêmico.

A prática de ensino, em duas disciplinas Prática I e Prática II, com duração de 300 horas, de acordo com a LDB 9394/1996, distribuídas ao longo de todo o curso, deveria ser oferecida pelos Departamentos de Química, Física e Matemática, tendo sua supervisão realizada por professores dessas áreas, com experiência docente não apenas no ensino superior, mas também na educação básica. Essa prática deve ser desenvolvida em escolas de educação básica, tanto da rede pública como particular, sempre sob a orientação do professor supervisor. Essa orientação, segundo a Resolução, não deve ultrapassar $25 \%$ do total da carga horária destinada à prática de ensino.

$O$ ingresso dos alunos em cada um dos cursos pretendidos deveria ser feito a partir do exame cuidadoso do histórico escolar de cada candidato, feito dentro do próprio departamento responsável pela licenciatura visada.

O curso foi implantado em 1999, contando com uma boa procura, tanto no primeiro quanto no segundo semestre, atendendo a aproximadamente 25 alunos. No primeiro semestre do ano 2000, 36 alunos se matricularam: 18 licenciandos em Matemática, 12 em Física e 6 em Química. O perfil dos alunos do curso compõe-se, basicamente, por profissionais já avançados em sua carreira de engenheiros, que gostariam também de se tornarem professores. Alguns já possuem experiência docente em nível superior. Muitos são professores particulares. Quatro alunos já possuem o título de mestre e um o de doutor. Há seis estudantes que já são aposentados e procuram a Licenciatura Especial, não apenas para desenvolverem uma atividade profissional nesta nova fase de suas vidas, mas porque sempre tiveram inclinação para o magistério, segundo declararam. 
Procurou-se adequar os horários das disciplinas oferecidas na nova licenciatura às disponibilidades dos profissionais que compõem as turmas. Em geral, as aulas têm sido oferecidas no período noturno ou ao final da tarde. Os horários da prática de ensino, apesar de serem bastante flexíveis, têm exigido um esforço de compatibilização por parte dos alunos com seus horários de trabalho. Entretanto, isso não tem representado um empecilho para a continuidade do curso. Mais de 40 candidatos se matricularam no curso em 1999 e 2000, sendo que 37 mantiveram suas matrículas, dentre os quais 15 já completaram sua licenciatura.

\section{Vivendo e aprendendo}

Desde o período de seu planejamento a experiência da nova licenciatura nos ofereceu oportunidades de aprendizagem. Logo de início foi a surpresa de ver a proposta de criação do novo curso partir de um departamento de engenharia. O Decanato do Centro Técnico e Científico, CTC, acolheu bem a idéia e tratou de passá-la para os departamentos possivelmente envolvidos: Física, Matemática e Química, além do de Educação. As discussões, que se estenderam por todo o ano de 1998 entre os representantes desses departamentos, foram carregadas de lições, constituindo uma rara oportunidade de troca, entre profissionais com distintas formações, voltados para um objetivo comum, a formação de professores por meio de um novo curso. Há muito tempo estudiosos da área de educação vêm apontando a falta de prioridade dada pela universidade à tarefa de formação de professores, dentro de uma ótica que privilegia claramente as funções ligadas à pesquisa, em detrimento das ligadas ao ensino (Candau, 1997; Lüdke, 1997). A PUC-Rio, como universidade de reconhecido prestígio e forte vocação para a pesquisa, não constitui exceção a esse respeito. Uma iniciativa na direção da formação de professores, por parte de membros do Centro Científico e Tecnológico se reveste, portanto, de um significado especial. Levanta-se logo a idéia do senso prático dos engenheiros, atentos a um mercado de trabalho cada vez mais rarefeito. Mas é preciso reconhecer que a iniciativa ensejou a profissionais das áreas de Física, Matemática e Química, além dos da Engenharia, uma oportunidade de envolvimento na discussão de uma questão vital para sua própria continuidade, para a qual talvez eles mesmos não tivessem ainda atentado tão claramente. A falta de professores para essas áreas, no ensino médio, vai acarretar, por sua vez, no futuro, a falta de estudantes interessados em prosseguir seus estudos dentro delas, para se tornarem professores ou pesquisadores. Assim, é da própria sobrevivência daqueles 
departamentos que se está tratando, ao propor uma nova via de formação de professores para aquelas áreas. Estava assim armado um cenário vivo para discussão de um dos pontos mais calorosos do debate hoje corrente na comunidade educacional: o papel da universidade na formação de professores. $\mathrm{E}$ os protagonistas dessa cena não eram apenas, como de costume, os representantes da educação.

Em estudo realizado por uma equipe de professores e estudantes do Departamento de Educação da mesma PUC-Rio, há mais de 10 anos (Candau, 1988), do qual participei, foram estabelecidas, por meio do estudo de três casos de inovação em licenciatura, algumas constatações cuja validade e pertinência continuam firmes até hoje. Entre elas estava a percepção de que a responsabilidade pela formação dos professores para as áreas científicas (Física, Química, Matemática, Ciências) deveria recair predominantemente sobre os especialistas dessas áreas, ou seja, o eixo do processo formador do futuro profissional deveria se orientar pelo ângulo desses especialistas. Eles são os que dominam as nuances do conhecimento específico da área e como ele se construiu através da história, podendo assim introduzir o futuro formador nessa perspectiva de construção do conhecimento científico, tão importante para o seu trabalho docente junto aos alunos da educação básica. As reuniões de planejamento da nova licenciatura representaram boa oportunidade para se discutir esse tema, mas também para constatar as dificuldades implicadas em um bom equacionamento do problema que ele envolve. O reconhecimento da necessária orientação daquele eixo não basta para que se desenvolvam os recursos para o seu cumprimento ao longo do curso formador. A implantação e o desenvolvimento da nova proposta de licenciatura vão ilustrando as dificuldades encontradas e as tentativas de enfrentá-las.

Uma dessas dificuldades está no próprio planejamento das disciplinas propostas. Enquanto na educação foram organizadas novas disciplinas sínteses, que se aproximam dos núcleos indicados na Resolução n. 2/97, que deu origem à nova modalidade de curso, nos outros departamentos, de início, se pensou em aproveitar ao máximo as disciplinas já oferecidas na licenciatura regular e no bacharelado, fazendo com que os engenheiros-alunos nelas se inscrevessem. À medida que o curso avançava, porém, foram surgindo sinais que reivindicavam um tratamento específico para as disciplinas destinadas aos novos alunos. Foi o que ocorreu na Licenciatura em Física com a disciplina Estrutura da Matéria, que ao final do primeiro ano do curso, 1999, foi considerada insuficiente para cobrir o conteúdo previsto para o trabalho com os alunos do ensino médio. Para o ano seguinte, 2000, foi proposto então que ela fosse reorganizada, sob a denominação de Física Contemporânea, que acabou sendo desdobrada em duas 
disciplinas obrigatórias. A disciplina Instrumentação para o Ensino Médio também foi desdobrada, assim como a disciplina Prática de Ensino, para cobrir o domínio das novas tecnologias utilizadas no trabalho docente e uma série de disciplinas denominadas eletivas de orientação são oferecidas ao aluno, de acordo com a avaliação de seu histórico escolar, feita pela coordenação do curso. Em geral, são disciplinas ligadas ao trabalho em laboratório e também a um programa desenvolvido pelo Departamento de Física da PUC-Rio junto aos estabelecimentos de ensino médio, o PIUES (Programa de Integração Universidade-Ensino Secundário). Essas e outras iniciativas indicam o esforço efetivo de um departamento, tradicionalmente voltado para a pesquisa e a formação de pesquisadores, para se aproximar das exigências de um curso voltado para a formação de professores.

$\mathrm{Na}$ licenciatura em Matemática também se registram esforços nesse sentido. $\mathrm{O}$ caso da disciplina Introdução à Análise ilustra isso muito bem. No primeiro semestre do ano 2000 ela foi oferecida como habitualmente, para alunos do curso de Bacharelado, da Licenciatura Regular e da Especial para Engenheiros e até para alunos da pós-graduação. Tendo completado seu curso de engenharia há 10 ou 15 anos, os alunos da Licenciatura Especial mostraram muita dificuldade para acompanhar com sucesso a disciplina. Ao final do semestre quase todos não alcançaram nível de desempenho satisfatório para serem aprovados. Analisando a situação, o departamento em conjunto com a professora ("excelente"!, no dizer do meu entrevistado) resolveram oferecer novamente a disciplina no segundo semestre, entāo com um grupo formado apenas pelos "engenheiros", que receberam tratamento exclusivo e muito adequado, sem que tivessem que pagar novamente pelo curso. Na opinião de meu entrevistado, recém diplomado, o curso correspondeu muito bem à necessidade de preparação em alto nível do futuro professor na matéria. "Não é exatamente o que ele vai ensinar aos alunos do ensino médio, mas é indispensável para a sua preparação adequada. Uma vez vencida a dificuldade inicial, entra-se na matéria e se cresce com ela para sempre". Ela se revela, ainda segundo o entrevistado, muito útil para o exame crítico do material didático disponível para o trabalho no ensino médio, de modo especial os muitos livros que disputam o mercado atualmente.

A Prática de Ensino na nova modalidade de licenciatura tem constituído uma importante fonte de lições, como campo de experimentações e sugestões para se discutir alternativas ao velho problema da combinação entre teoria e prática na formação de professores. A própria LDB de 1996 já estipula a integração das atividades práticas ao longo de todo o curso de licenciatura e aumenta sua carga horária para 300 horas. Continua, entretanto, por fazer um 
esforço mais efetivo de nossa parte, membros da comunidade educacional, no sentido de compreender melhor um esquema que corresponda adequadamente à concepção de "prática de ensino", condizente com o perfil do professor que queremos formar hoje.

Este é um tema recorrente nas discussões dos estudiosos da formação de professores, constituindo um contínuo desafio até o presente. A professora Silke Weber, membro do CNE, apresentou em 1997, por solicitação da Câmara do Ensino Superior, uma proposta para articulação das 300 horas de Prática de Ensino previstas pela LDB, que obteve aprovação no Plenário do CNE, mas, ao que parece, até hoje não foi homologada pelo Ministro da Educação. Ela teve, entretanto, grande divulgação por todo o País, sendo inspiradora de planos curriculares de muitas instituições ensino superior, algumas delas por certo ensaiando soluções inovadoras nesse campo.

Pode-se considerar que a Licenciatura Especial em Física da PUC-Rio está incluída nesse rol de instituições que buscam alternativas para o complexo problema da Prática de Ensino. Ela está enfrentando os clássicos problemas de difícil integração entre preparação teórica e prática e de entrosamento com as escolas do ensino médio com criatividade e competência, dando prova de uma tenacidade que pode servir de exemplo. $\mathrm{O}$ binômio teoria $\mathrm{x}$ prática está sendo construído com o auxílio do trabalho do próprio professor de Prática, em sua tarefa de supervisão e por meio de outras disciplinas que ele mesmo leciona no departamento. Ele tem o doutorado em Física e longa experiência de ensino no nível médio e também no superior. As fragilidades da formação trazida pelo aluno-engenheiro são assim cobertas pelo trabalho do professor. Os alunos são solicitados para elaborarem um programa para o curso de Física no ensino médio, a partir da análise crítica dos compêndios disponíveis. As propostas e as análises críticas são discutidas individualmente com o professor de Prática e no grupo de alunos-engenheiros. São também assim avaliados outros materiais disponíveis para o ensino médio, como filmes, kits, roteiros de laboratórios, softwares etc. São feitas visitas a museus, centros de estudos e universidades.

Quanto à parte relativa ao entrosamento com as escolas, pela qual se assegura (ou não) a prática docente efetiva, ainda as soluções deixam muito a desejar, como afirmou o professor de Prática de Ensino em nossa entrevista. Esse entrosamento é dificultado de ambos os lados: no das escolas, que não vêem com facilidade a entrada do estagiário em sala de aula e muito menos a possibilidade de que assuma uma disciplina, ou ao menos parte dela. No lado da universidade, porque não prevê um tempo suficiente para o trabalho do professor de Prática de Ensino, para que ele pudesse dar conta de todas as suas atribuições. 
De maneira bastante criativa, nosso professor procurou contornar da melhor forma possível essas dificuldades, seja pelo contato direto, pessoal e constante com as escolas, seja pelo investimento na criação do que ele chama de "parceiro certo", isto é, o orientador local, professor da escola visada para o estágio, que seja escolhido pela sua competência e que aceite entrar na parceria com o professor da universidade na orientação do estudante. Nosso professor de Prática está avançando, sem o saber, em um domímio hoje muito estudado por teóricos no campo da formação de professores, especialmente em outros países. Fala-se muito na França e no Canadá do "partenariat", e nos Estados Unidos e Inglaterra do "partnership", que começa a aparecer como uma das possíveis vias de aproximação entre a universidade e a escola de educação básica. A figura do professor-parceiro é chave para esse processo, e para configurá-la é preciso muita dedicação e cuidado por parte do professor de Prática de Ensino, além do tempo despendido com a visita às escolas e a permanência nelas, observando o trabalho de professores e dos alunos estagiários. Este é um novo campo de estudos, que está pedindo atenção e poderá oferecer boas contribuições para os problemas da formação de professores. Quero por ora ainda comentar a dificuldade de assegurar ao estagiário o direito ao exercício de uma prática docente, ainda que seja parcial, para que ele possa conhecer suas próprias dificuldades, enquanto pode contar com uma supervisão que o ajude a superá-las.

O caso dos engenheiros em formação para se tornarem professores oferece material muito pertinente para se discutir a grande questão do aproveitamento da experiência anterior do formando, seja em termos de escolaridade ou de trabalho. Esse aspecto continua representando um desafio para os coordenadores dos departamentos envolvidos na Licenciatura Especial da PUC-Rio e para todos os que se dedicam a estudar a delicada questão da competência e do saber docentes. Os coordenadores reclamam, com razão, do tempo que têm de despender no exame cuidadoso do histórico escolar de cada candidato, para poder planejar seu currículo no novo curso, uma tarefa por certo inesperada na carreira de um pesquisador em Física... O outro lado da questão, bem mais complicado, só vou indicar aqui: como visualizar a soma de saberes acumulados pelo estudante, no caso um profissional da engenharia, com amplo exercício nessa área. E como esse acumulado poderia se aliar ao que se espera do professor e da sua competência como profissional. Sei que a questão é complicada, inclusive porque também me interesso pelo estudo da socialização profissional de professores, o qual me permite vislumbrar a dificuldade de atribuição desse conceito ao trabalho do professor. Deixo em aberto essa questão para aprofundamento em outro trabalho. 
Quero tocar ainda num ponto delicado, trazido à tona pelos dois entrevistados recém formados. Apesar de reconhecerem seu distanciamento de certas matérias teóricas, por terem se diplomado em engenharia há algum tempo já, eles não se vêem como menos habilitados do que os seus jovens colegas da licenciatura regular, para desenvolverem uma preparação adequada ao exercício do magistério. Sob o ponto de vista teórico, eles consideram que as lacunas podem e devem ser preenchidas por um bom planejamento do currículo, como aliás deveria acontecer em todo curso de licenciatura. Sob o ponto de vista da prática eles vêem, tal como fazem os estudiosos do tema, o problemachave da formação do futuro professor, com as dificuldades já apontadas. Ainda acrescentam um temor especial de lidar com alunos situados na época difícil da adolescência, o que fez os dois entrevistados afirmarem que o que mais temem é não possuir o domínio de turma. Isso os levou a considerar que as matérias do conjunto da educação estão sendo realmente reveladoras e fundamentais para a sua formação, enquanto das específicas ainda esperam por um maior entrosamento e efetividade. Quanto à defasagem no domínio do conteúdo, ambos consideram que tanto com relação a si próprios, como a seus colegas, todos são plenamente capazes de superá-la, pela maturidade e capacidade de orientar sua própria aprendizagem. Aliás, a maturidade da turma não deve ser considerada fator secundário, pois contribui decisivamente para assegurar dedicação, atenção e responsabilidade pelo processo de formação pelo qual estão passando, já em uma época da vida na qual as opções são feitas com muito escrutínio. Como professora de três turmas, devo dizer que o fator maturidade, experiência acumulada na vida e na profissão, é por certo muito positiva no trabalho com certas questões educacionais discutidas nos cursos em que lecionei.

\section{Concluindo}

Ao encerrar este texto, quero assinalar que ele trata de um assunto apenas iniciado, longe portanto de qualquer fecho. Trouxe para ele uma série de questões extraídas da vivência de um curso novo e inovador. Fui e ainda sou contra a sua proposta, apresentada ao CNE como uma solução para os problemas da formação de professores para certas disciplinas que estão a descoberto no ensino médio. Continuo a reclamar, como então, uma política que compreenda a valorização do magistério, em termos de salário, condições de trabalho e carreira, para que ele possa assumir com dignidade o papel importante que lhe cabe no desenvolvimento de nosso país. Vejo, entretanto, essa nova modalidade de licenciatura como uma experiência em caráter de emergência, que não deve se 
perpetuar, mas cuja vivência pode ensejar o ensaio de alternativas, que poderão se revelar válidas para aproveitamento em outros cursos, em especial na Licenciatura Regular, tão cheia de problemas reconhecidos há muito tempo.

Um dos pontos de maior concentração crítica por parte da comunidade educacional na época do lançamento dessa nova modalidade de curso foi a sua curta duração, o que levou às vezes a aproximá-la da antiga "Licenciatura Curta", de marca tão negativa em nossa história educacional. Na verdade, a duração da nova modalidade nunca fica reduzida ao mínimo de 540 horas, e ainda se compõe com as muitas horas já cursadas pelo candidato, em seu curso de engenharia, em matérias específicas e relacionadas com a área da licenciatura prevista. Claro que este processo é diretamente dependente do cuidado com que é examinado o histórico escolar do candidato, pela instituição que oferece o novo curso. E esse curso, por sua vez, tem sua qualidade intrinsecamente ligada à reputação já estabelecida pela instituição e o cuidado que ela tem em preservá-la.

\section{Referências}

CANDAU, Vera Maria F. Magistério: construção cotidiana. Petrópolis: Vozes, 1997. Universidade e formação de professores: que rumos tomar?, p. 30-50.

CANDAU, Vera Maria F.(Coord.). Novos rumos da licenciatura. Relatório final de pesquisa. Departamento de Educação, PUC-Rio, 1988.300 p.

LÜDKE, Menga e AUTRAN, Ilza Maria Ferreira Pinto. O curso de licenciatura da PUCRio: uma experiência a ser compartilhada. In: SOUZA, Donaldo Bello de e FERREIRA, Rodolfo (Orgs.). Bacharel ou professor? O processo de reestruturação dos cursos de formação de professores no Rio de Janeiro. Rio de Janeiro: Quartet, 2000. p. 135-144. LÜDKE, Menga. O CNE e as novas propostas para a formaçāo de professores: uma visão de dentro. In: SILVA, Waldeck Carneiro da (Org.). Formação dos profissionais da educação: o novo contexto legal e os labirintos do real. Niterói, RJ: EdUFF, 1998, p. $35-48$.

LÜDKE, Menga. Avaliação institucional: formação de docentes para o ensino fundamental e médio (as licenciaturas). In: Estudos e Debates, n.19. Brasília: CRUB, 1997, p. 137-196.

Recebido em: 09.04.2001

Aceito em: 22.10 .2001 
